\title{
Socio-political prioritization of bioenergy with carbon capture and storage
}

\author{
Mathias Fridahl \\ Journal Article
}

\section{Tweet}

N.B.: When citing this work, cite the original article.

Original Publication:

Mathias Fridahl , Socio-political prioritization of bioenergy with carbon capture and storage, Energy Policy, 2017. 104(), pp.89-99.

http://dx.doi.org/10.1016/j.enpol.2017.01.050

Copyright: Elsevier

http://www.elsevier.com/

Postprint available at: Linköping University Electronic Press

http://urn.kb.se/resolve?urn=urn:nbn:se:liu:diva-134383

(c)

H.U UNNGERSGS 


\section{Socio-political prioritization of bioenergy with carbon capture and storage \\ Mathias Fridahl}

Linköping University, Department of Thematic Studies - Environmental Change, Centre for Climate Science and Policy Research (CSPR)

mathias.fridahl@liu.se, +46705643372

\section{Abstract}

Limiting global warming to well below $2^{\circ} \mathrm{C}$ requires the transformation of the global energy system at a scale unprecedented since the industrial revolution. To meet this $2^{\circ} \mathrm{C}$ goal, $87 \%$ of integrated assessment models opt for using bioenergy with carbon capture and storage (BECCS). Without BECCS, the models predict that the goal will be either unachievable or substantially more costly to meet. While the modeling literature is extensive, studies of how key climate policy actors perceive and prioritize BECCS are sparse. This article provides a unique intercontinental mapping of the prioritization of BECCS for the long term transition of the electricity supply sector. Based on survey responses from $711 \mathrm{UN}$ climate change conference delegates, the article reports the low prioritization of BECCS relative to alternative technologies, indicating an urgent need for studies of the socio-political preconditions for large-scale BECCS deployment.

Keywords: Bioenergy with carbon capture and storage (BECCS); Electricity supply; Transition management; Transformational change; UNFCCC. 


\section{Introduction}

The UN Framework Convention on Climate Change (UNFCCC) has set an ambitious goal for world politics in the twenty-first century: to hold the average global temperature increase at the end of the century to well below $2{ }^{\circ} \mathrm{C}$ relative to pre-industrial levels (UNFCCC, 2016). With current human-induced warming of roughly $0.85^{\circ} \mathrm{C}$, approximately 3.9 billion people in energy poverty, and a high likelihood that world population will continue to grow throughout this century, meeting energy demand while radically reducing emissions requires societal transformation at scales unprecedented since the industrial revolution (Gerland et al., 2014; González-Eguino, 2015; IPCC, 2014).

In this context, the combination of carbon capture and storage (CCS) technologies with energy production from biomass - so-called BECCS - is proposed as a promising mitigation technology for supplying energy or goods to end users while removing carbon dioxide $\left(\mathrm{CO}_{2}\right)$ from the atmosphere. The logic is simple: as plants grow they encapsulate atmospheric $\mathrm{CO}_{2}$ in biomass that is harvested and used to produce, for example, electricity, heat, biofuels, and pulp/paper. Instead of allowing the $\mathrm{CO}_{2}$ to recirculate into the atmosphere, it is captured, transported, and deposited in long-term geological storage sites (IPCC, 2014).

In theory, if harvested biomass is regrown, BECCS can achieve anything from reduced global emissions to net-negative emissions (Gough and Upham, 2011). The highest potential is identified in the electricity sector (IEA, 2011b; Tokimatsu et al., 2016). Furthermore, of all scenarios associated with a high (i.e. 66\%) likelihood of achieving the $2{ }^{\circ} \mathrm{C}$ goal, $87 \%$ include large-scale BECCS deployment (Fuss et al., 2014).

While many models try to address technical and economic uncertainties through parameterization or by incorporating, for example, explicit land use modeling components, models often fail to address non-technical uncertainties related to, for example, politics and governance. Given that the technical and economic uncertainties are high enough to call into question the scale at which BECCS is applied in the models (Kemper, 2015), the fact that very little is known of the legitimacy aspects of BECCS is daunting (Dowd et al., 2015). Deploying BECCS at the scales suggested by the models will probably require government involvement, for example, by regulating markets to establish a sufficient carbon price that incentivizes deployment, by potential $R \& D$ investments, and by subsidizing negative emissions. Carbon taxes, which do not distinguish the origin of $\mathrm{CO}_{2}$ emissions (i.e. fossil or biotic), have been evaluated to be more efficient drivers of both fossil CCS and BECCS deployment than, for example, taxes on fossil fuels. To further incentivize BECCS, a $\mathrm{CO}_{2}$ tax could be combined with instruments that also reward negative emissions, such as subsidies (Ricci, 2012; Vergragt et al., 2011; Zheng and $\mathrm{Xu}, 2014)$. It is also at least somewhat possible to incentivize BECCS by generating tradable credits based on negative emissions in emissions trading systems and by being allowed to account for negative emissions from BECCS to comply with commitments under the UNFCCC (Carbo et al., 2011; Grönkvist et al., 2006).

Governments as well as non-governmental actors are therefore potentially of great importance for the future of BECCS, especially if existing market drivers are too weak. Despite this, international comparative studies of how BECCS is prioritized by 
governments and civil society in different world regions are nonexistent. This article therefore asks:

- How is BECCS prioritized, compared with other technologies, for the long-term transition of electricity supply systems toward low-carbon configurations?

- Do priorities in different world regions correlate with the regions' technical potential for BECCS?

- Do priorities for BECCS differ among actor types?

Through addressing these questions, the article provides a preliminary international comparison of certain proxies for understanding the legitimacy of BECCS. The article focuses on the role of BECCS in the transition of national electricity supply systems, the sector with the highest technical potential for BECCS. Given that awareness of CCS and BECCS is generally low among the public (Ashworth et al., 2013; Dowd et al., 2015), the article targets actors actively involved in climate policy making by assessing survey responses from 711 UN Climate Change Conference delegates regarding technology preferences for investments in the long-term (i.e. 25-50 years) transition of electricity generation. Section two reviews current research into BECCS. Section three presents the data collection method and how the data are broken down by region and actor type. Section four highlights the main results, indicating that preferences for BECCS differ depending on the respondents' regional origins and actor types and that regional preferences correlate with regional technical potential for BECCS. Section five discusses the results in light of the current literature on BECCS. Section six concludes the article, demonstrating that BECCS has a low priority relative to other technology options, which in turn indicates an urgent need to improve our understanding of the legitimacy of BECCS.

\section{Bioenergy with carbon capture and storage (BECCS)}

The literature outlines several technologies for separating and capturing $\mathrm{CO}_{2}$ from fossil and biomass fuels, all of which are associated with high costs and energy penalties (IEA, 2014; Leung et al., 2014). Although CCS can be used at any point source, it is more economically feasible at large- than small-scale sources (Wennersten et al., 2014). Storage of $\mathrm{CO}_{2}$ has been piloted and demonstrated, incentivized by enhanced oil recovery and by carbon taxes in combination with regulations governing the maximum $\mathrm{CO}_{2}$ content of natural gas, ${ }^{1}$ but other forms of geological storage are also being researched and demonstrated (IPCC, 2005; Kemper, 2015). In relation to biomass use, CCS potential is highest in electricity and heat production, but pulp/paper and biofuel production may also be eligible (Carbo et al., 2011; Gough and Upham, 2011; Klein et al., 2011; Vergragt et al., 2011). To date, however, low carbon prices have made BECCS uncommercial. A schematic of the most commonly discussed components of BECCS technology systems is provided in Fig. 1.

${ }^{1}$ For an example of a CCS demonstration project incentivized by a $\mathrm{CO}_{2}$ tax in combination with market standards for the $\mathrm{CO}_{2}$ content of natural gas, see the Norwegian Sleipner West gas field (Karimi et al., 2012). 
Fig. 1. Schematic of the most commonly discussed components of BECCS technology systems outlined in the scientific literature.

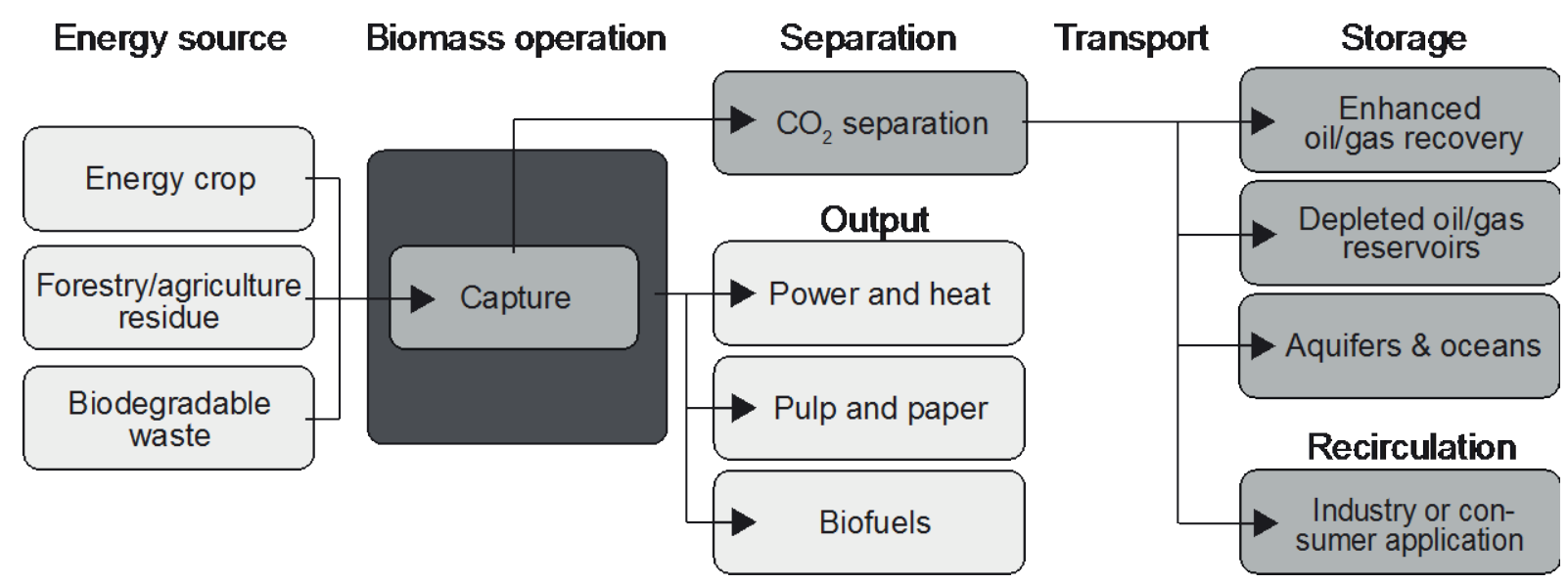

\subsection{BECCS and integrated assessment modeling}

BECCS contributes significantly to most model runs associated with the IPCC Representative Concentration Pathway (RCP) 2.6. Under RCP 2.6, temperature increase above $2^{\circ} \mathrm{C}$ by the end of the century relative to the $1850-1900$ average is unlikely (Clarke et al., 2014). In 2100, RCP 2.6 corresponds to 421 ppm of $\mathrm{CO}_{2}$ in the atmosphere, with preindustrial levels of approximately $280 \mathrm{ppm}$ and current levels of approximately $400 \mathrm{ppm}$. As the global annual increase in atmospheric $\mathrm{CO}_{2}$ concentration has been roughly $2 \mathrm{ppm} / \mathrm{year}$ over the last decade, it is increasingly clear that stabilizing concentrations at the levels estimated to be required to keep the global mean surface temperature increase below $2^{\circ} \mathrm{C}$ will require the large-scale decarbonization of the global energy system. Furthermore, most of the increase in radiative forcing since 1750 can be attributed to the increase in the atmospheric concentration of $\mathrm{CO}_{2}$ (IPCC, 2013).

Fully $87 \%$ of all scenarios $(n=116)$ consistent with RCP 2.6 in the IPCC's Fifth Assessment Report require global net negative emissions in the 2050-2100 period (Fuss et al., 2014). This is achieved when "the negative emissions associated with BECCS are greater than total emissions from all other sources" (Gough and Vaughan, 2015: 7). Given that BECCS is currently only entering the demonstration phase, these are astonishing requirements.

The attraction of BECCS is its theoretically relatively high potential to generate global net-negative emissions that allow a temporary overshoot of $\mathrm{CO}_{2}$ concentrations in the atmosphere, above $420 \mathrm{ppm}$, in the first half of the twenty-first century (Azar et al., 2013). If BECCS is excluded from the options of the models, the goal is out of reach or can only be achieved at substantially higher costs (Azar et al., 2010, 2013; Selosse and Ricci, 2014).

\subsection{Key uncertainties contextualizing assessments of BECCS' techno-economic potential}

Several uncertainties are listed in the literature as contextualizing assessments of both the technical and economic potential of BECCS. A first set of uncertainties relates to sustainable biomass production and climate dynamics. The modeled role of BECCS 
depends on both the future availability and price of biomass, both of which are highly uncertain. Estimates of biomass availability and pricing are driven by the relative weights assigned to competition for land for other purposes (e.g. biological diversity and food production), water, and fertilizers (Azar, 2011; Gough and Upham, 2011; Popp et al., 2014; Williamson, 2016). The unknown impact of climate change on biomass availability as well as nonlinearities in terrestrial and ocean uptake of carbon exacerbates uncertainties (Azar et al., 2013; Fuss et al., 2014). Finally, biomass production on land with high carbon stocks as well as potential indirect emissions from, for example, deforestation undermine the negative emission potential (Azar, 2011).

Second, knowledge gaps concerning available storage capacity and risks introduce further uncertainties. Estimates of the global storage capacity range from 100 to 10,000 $\mathrm{GtCO}_{2}$, with outliers up to 200,000 $\mathrm{GtCO}_{2}$ (Ansolobehere et al., 2007; Bradshaw et al., 2007; Humpenöder et al., 2014; IPCC, 2005; Selosse and Ricci, 2014). Potential longterm physical leakage ${ }^{2}$ from storage is another uncertainty. Storage has traditionally been piloted in combination with enhanced oil or coal bed methane recovery, but examples of storage for mitigation purposes exist as well, driven primarily by a tax on $\mathrm{CO}_{2}$ (IEA, 2014; Karimi et al., 2012). Natural sites of $\mathrm{CO}_{2}$ and pilot projects have displayed low leakage, yet for mitigation purposes, storage needs to be assured on timescales different from those of enhanced oil or gas recovery (Jenkins et al., 2012). Issues of insurance and responsibilities related to, for example, monitoring and accidents triggered by unforeseen events (e.g. earthquakes) also require attention (IPCC, 2005; Zoback and Gorelick, 2012).

Third, little is known of the economies of scale related to BECCS. While BECCS can benefit from economies of scale in capital costs, large-scale operational units also incur diseconomies of scale in biomass supply and transportation. In cases in which biomass availability and geological storage capacity are co-located, transportation infrastructure is well developed, and competition for biomass is low, the suggested optimal scale of BECCS is relatively large. In other cases, it may be limited to smaller operational units, making capital costs (e.g. for installing $\mathrm{CO}_{2}$ capture technologies) higher per unit of produced output (e.g. electricity) than those of larger fossil CCS or co-fired units (Gough and Upham, 2011; Sanchez and Callaway, 2016). Compared with fossil fuels, the energy content of biomass is also generally lower, which increases costs of transportation per unit of energy. This can partly be addressed through pretreatment such as pelletizing, yet this too incurs additional costs (Luckow et al., 2010; Sanchez and Callaway, 2016). However, very little is yet known of the optimal scale of BECCS facilities, not least because of the lack of spatially explicit high-resolution modeling of BECCS deployment.

Fourth, most assessments make investments in BECCS commercially viable only at currently unrealistically high carbon prices or with strong regulation (Azar et al., 2013; Fuss et al., 2014; Haszeldine, 2009). Co-firing of fossil fuel and biomass with CCS offers more competitive alternatives, yet current carbon prices still fall far short of those required to provide a strong investment incentive (Gough and Upham, 2011; Selosse

\footnotetext{
2 Physical leakage is distinct from the concept of international leakage, which refers to increases in global emissions as an effect of domestic mitigation actions. For example, if demand for fossil fuels decreases in one part of the global energy system, global prices of fossil fuels could fall, leading to increased consumption in other parts of the system.
} 
and Ricci, 2014). Besides low carbon prices, current accounting rules for international commitments, emissions trading schemes, and carbon taxes constitute other barriers as they do not recognize negative emissions (Carbo et al., 2011; Gough and Upham, 2011; IEA, 2011a).

\subsection{Previous studies of techno-economic potential}

It is in this context that the modeled techno-economic potential exists. The combined techno-economic potential for negative emissions is assessed to be in the range of 3-20 Gt $\mathrm{CO}_{2}$ /year, around mid century (Azar et al., 2010; IEA, 2011b; IPCC, 2005 Kemper, 2015). Kemper (2015) rates the International Energy Agency's Greenhouse Gas R\&D Programme (IEAGHG) as a mid-range assessment of high quality in terms of the details considered, allowing for more detailed breakdowns and a more nuanced, regionalized, and technology-specific representation of the global energy system.

In estimates of the technical potential for BECCS, it is common to factor in aspects such as storage capacity, biomass availability, and technical performance, without reference to, for example, costs, barriers, or policies. Economic potential, on the other hand, also takes costs into account, by evaluating how much energy can be converted at a lower cost by BECCS than by reference technologies. The economic potential of BECCS is usually assessed as much lower than the technical potential (IEA, 2011b; IPCC, 2011; Kemper, 2015). In IEAGHG's rating of the technical and economic potential of BECCS, the economic potential is approximately $1 / 3$ of the technical potential, i.e. high relative technical potential compared with other regions correlates with high relative economic potential (IEA, 2011b).

It should be noted that economic potential is often distinguished from market or commercial potential (IEA, 2011b; IPCC, 2011). The latter also tries to account for obstacles and drivers induced by, for example, regulation and subsidies. A market potential for BECCS that is lower than its economic potential may follow from many of the uncertainties discussed above, which make for weak price signals and inadequate accounting rules. However, the opposite can also hold true, i.e. that the market potential is higher than the economic potential due to the development of future policy incentives in favor of BECCS. If, for example, negative emissions can be accounted for in cap-andtrade systems or are subsidized, the market potential increases.

IEAGHG's assessment of the economic potential assumes a carbon price of $€ 50 /$ metric ton. In comparison, the price of one metric ton of carbon under the EU Emissions Trading System averaged approximately €4.5 in the first two weeks of December 2016. Under current market conditions, the vast majority of the technical potential for BECCS is simply not commercial. Few indicators suggest that the price signal or international regulation will suffice for market forces to drive the development and deployment of BECCS at scale. If this is true, the mobilization of BECCS at the levels suggested by the models will be dependent on national or regional political decisions regulating the market in favor of BECCS. Developing a technology such as BECCS to the point of commercial viability takes a long time. As market drivers are currently lacking and will likely remain so for the coming decade, policy drivers are vital. It is therefore desirable to know more about the legitimacy aspects and relative prioritization as they may act as a brake on, or accelerator of, BECCS in the event that carbon price signals are too weak or lacking to incentivize deployment. 


\subsection{Previous studies of prioritization and perceptions of BECCS}

Attitudes toward the role of BECCS in low-carbon transitions across various stakeholder groups are poorly understood, however. There have been numerous studies of the public acceptance of CCS whose results are potentially applicable to BECCS (Ashworth et al., 2013; L'Orange Seigo et al., 2014; Wennersten et al., 2014). These studies confirm a general pattern of both low public familiarity with and negative preferences for CCS (Kemper, 2015). The studies find, for example, considerable "not-in-my-backyard" resistance from local communities through which transportation pipes are planned or under which storage sites have been identified. Resistance is also strong among environmental NGOs, which, for example, see a risk of CCS being used to extend the fossil fuel era and of leakage from storage sites.

To date, studies of the public understanding of BECCS are limited (Dowd et al., 2015; Kemper, 2015). However, BECCS has features, such as the promise to deliver net-negative emissions, distinct from those of fossil CCS, conferring other types of benefits, risks, and uncertainties (cf. Wallquist et al., 2012). These differences can yield characteristic patterns of resistance or acceptance that justify targeted studies. Still, Zheng and $\mathrm{Xu}$ (2014) "conclude that political barriers and public acceptance are the major distinctions" (p. 5221) between a new CCS technological paradigm, including BECCS, and today's highly fossil-dependent global energy system.

It is well known that if a technology such as BECCS is to be commercially viable for largescale application in the second half of the twenty-first century, as recommended by the models for cost optimization of the $2^{\circ} \mathrm{C}$ goal or as its prerequisite, prioritizing large investments in such unproven technology is promptly required (Azar, 2011; Azar and Holmberg, 1995; Kemper, 2015; Zheng and Xu, 2014).

For many of the above reasons, it is pertinent to start mapping the prioritization of BECCS relative to other technology options for low-carbon transition. Dowd et al. (2015), in their review of the public acceptance of BECCS, conclude that the "lack of public perception and acceptance research into bioCCS may need to be rectified in order to reflect the relatively recent attention CCS with bioenergy has been garnering in the policy and modeling spaces" (p. 4035).

\section{Materials and methods}

One central arena for developing climate policy is the UNFCCC. There are good reasons to expect familiarity with CCS and BECCS to be higher among UNFCCC delegates than among the general public. The importance of BECCS for meeting global climate policy goals is a recurring theme in the UNFCCC. As UNFCCC conferences gather actors with climate expertise representing a diverse set of constituencies, from national and local government representatives to business actors, researchers, and environmental NGOs, it can be seen as a good testing ground for probing preferences regarding BECCS. If actors in this forum have low preferences for BECCS, warning flags for the large-scale deployment of BECCS in $2^{\circ} \mathrm{C}$ scenarios ought to be raised.

This article presents the first global mapping of how BECCS is prioritized by UNFCCC delegates. It focuses on differences or similarities in priorities among various actors from seven sub-regions of the global energy system and it compares BECCS with other low-carbon energy technologies. 


\subsection{Data collection and survey design}

The data were obtained through surveys conducted at two UNFCCC climate conferences: in Bonn, June 2015 and Paris, December 2015. The survey items on technology options for the long-term transition toward low-carbon electricity generation were part of the International Negotiations Survey, which has previously been used to explore, for example, leading actors in climate change negotiations (Karlsson et al., 2012), roles of non-state actors in climate change governance (Nasiritousi et al., 2014), effort sharing preferences (Fridahl and Linnér, 2015; Friman and Hjerpe, 2015), and alternative forums for tackling climate change (Hjerpe and Nasiritousi, 2015). The INS was initiated in 2007 and now has received over 9000 completed questionnaires. The questionnaires were distributed in person at the conference venues.

BECCS preferences were surveyed using a Likert-style response option format. Likert items measure attitudes toward options related to a stem statement, providing respondents with a bipolar weighting (Carifio and Perla, 2007; Likert, 1932). The respondents were asked to agree or disagree with the statement "In your country of residence, investments in a long-term (25-50 years) transition to low-carbon electricity generation should be directed toward" followed by ten individual Likert items to be prioritized relative to each other: "Bioenergy without carbon capture and storage (CCS)"; "Bioenergy with CCS"; "Fossil fuel with CCS"; "Hydropower"; "Nuclear power"; "Ocean power"; "Solar power"; "Wind power"; "Other, please indicate: ..."; and "None of the above, the electricity production system in my country of residence is already sufficiently low-carbon." The Likert items are selected based on assessments of their potential to contribute to the low-carbon transition of the global electricity production system (IEA, 2011b, 2013; IPCC, 2011, 2014).

The response scale ranged from one ("disagree strongly") to seven ("agree strongly"). The article follows the convention in the survey design literature of treating the middle option, "neither agree nor disagree," as reflecting indifference or ambiguity rather than as indicating "don't know" (Johns, 2005). It should be noted that the so-called acquiescence bias - i.e. a tendency among respondents to agree rather than disagree with a Likert statement - likely generated a slightly more positive response pattern than if the attitudes had been measured using other means (Schuman and Presser, 1981). Although this has an important effect when measuring absolute preferences, when measuring relative preferences - as is done here - the positive bias can be expected to be equal for all Likert items and to have no effect on the results.

\subsection{Actor types}

It is well known that societal transformations require the involvement of multiple actors in different roles at different levels of socio-technical systems (Geels, 2012; Smith et al., 2010). In this article, the actor dimension is not explored in detail, though several actor groups of great significance for transition management are part of the sample. These include state actors (i.e. negotiators from ministries and relevant line agencies, national government representatives, and representatives of intergovernmental organizations) and several categories of non-state actors (e.g. representatives of business, environmental, research, independent, trade union, gender, justice, youth, and indigenous peoples' NGOs). 
Table 1

Distribution of respondents by actor type at the UNFCCC negotiations.

\begin{tabular}{lc}
\hline Actor type & Number of respondents \\
\hline Negotiator & 54 \\
Representative of government (national and local) & 125 \\
Intergovernmental organizations (IGOs) & 64 \\
Environmental NGOs (ENGOs) & 136 \\
Business NGOs (BINGOs) & 41 \\
Research and independent NGOs (RINGOs) & 140 \\
Other NGOs (e.g. justice, gender, trade unions, youth, and & 136 \\
indigenous peoples' NGOs) & 15 \\
Unspecified actor type (N/A) & 711 \\
\hline Total & \\
\hline
\end{tabular}

Ideally, categorizing the actor types in greater detail than is statistically viable here would be desirable to improve our understanding of how various actors prioritize BECCS. Especially useful would be breaking down the data by actor types from the various regions. While this study provides a preliminary general mapping of the preferences of climate policy experts from all world regions participating in UNFCCC conferences, future studies could explore actor preferences in more detail, for example, by selecting a set of case studies identified through general surveys of priorities. It should also be noted that the sample includes more of some actors than others. This reflects the fact that different groups of actors are represented in different numbers in the target population (i.e. all UNFCCC conference delegates). For example, the relatively high number of ENGOs and lower number of BINGOs means that the preferences of ENGOs are given more weight than those of BINGOs (see Table 1). This should be kept in mind when interpreting the results.

\subsection{Regional breakdown of the data}

The techno-economic potential for BECCS varies across world regions depending, for example, on the availability of storage sites and biomass. The analysis subdivides respondents according to their affiliation with different sub-systems of the global energy system (cf. Table 2). Here, the regionalization is based on the geographical breakdown of the global energy system established by IEAGHG when assessing the regional technical and economic potential of BECCS to meet the $2^{\circ} \mathrm{C}$ goal, as described in section 2.2 above. The IEAGHG assessment addresses six BECCS technologies identified to have the highest potential, ranging from co-firing of biomass with pulverized coal in electricity production to biomass operations producing biofuels (IEA, 2011b). The negative emissions potentials are estimated for 2030 and 2050.

This breakdown enables exploration of the survey data to determine whether the role or geographical origin of respondents influenced the response pattern. Using the regions established by IEAGHG also allows comparison with the modeled technical potential of 
BECCS in these regions. The regions, numbers of respondents, and assessed technical and economic potential are reported in Table 2.

\section{Table 2}

Distribution of respondents and technical potential for negative emissions using BECCS by region.

\begin{tabular}{lccc}
\hline Region & $\begin{array}{c}\text { Number of } \\
\text { respondents }\end{array}$ & $\begin{array}{c}\text { Technical potential for } \\
\text { negative emission } \\
{\left[-1 \times \mathrm{Gt} \mathrm{CO}_{2 \mathrm{eq}}\right]^{\mathrm{a}}}\end{array}$ \\
\hline Africa and Middle East (AFME) & 98 & 2030 & 2050 \\
Asia (ASIA) & 62 & 4.1 & 8.6 \\
Latin America (LAAM) & 21 & 5.5 & 11.5 \\
Non-OECD Europe and former Soviet & 77 & 5.2 & 10.0 \\
Union (NOEU) & 87 & 1.6 & 2.8 \\
North America (NOAM) & 14 & 4.3 & 8.2 \\
Oceania (OCEA) & 234 & 1.4 & 2.4 \\
OECD Europe (OEU) & 118 & 1.9 & 3.5 \\
Unspecified country of residence & 711 & - & - \\
(N/A) & & 23.8 & 47.5 \\
\hline World total & & & \\
\hline
\end{tabular}

a Based on technical potential reported in IEAGGH (IEA, 2011b: Table D-9). Note that the technical potential figures listed here are sums of the technical potential of six alternative individual technology pathways for developing BECCS that are not easily additive in practice because they may compete for resources and substitute for each other. However, it does provide a good proxy for the relative technical potential of the regions.

b Reported world total potential for negative emissions assumes unconstrained transportation of captured $\mathrm{CO}_{2}$ between world regions, maximizing storage capacity.

Again, finer granularity would be desirable, and the national jurisdiction level would be ideal for more detailed studies. However, the regional level applied here provides a preliminary departure point for further discussions and allows comparison with regionalized global energy system model assessments of the role of BECCS in meeting the $2^{\circ} \mathrm{C}$ goal.

\section{Results}

\subsection{Global priorities for BECCS compared to other technology options}

Mean values of UNFCCC delegates' prioritization of investments in BECCS relative to other technology options for transition toward low-carbon electricity generation systems are shown in Fig. 2. 
Fig. 2. Preferences of UNFCCC delegates for investing in different technologies for longterm (2025-2050) transition to low-carbon electricity generation.

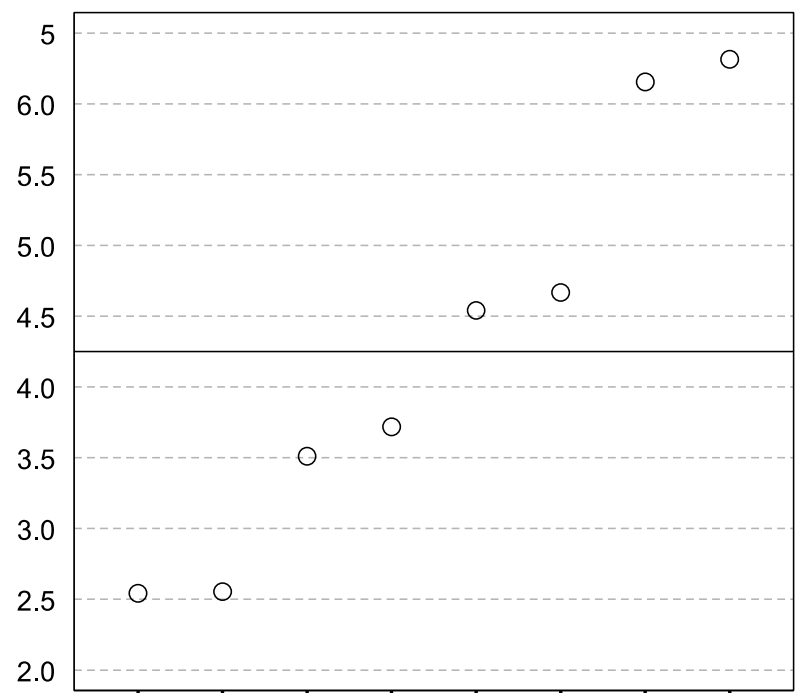

Note: The solid horizontal line represents the mean value for all technologies.

Fig. 3 illustrates how responses are distributed on the response scale ranging from strongly disagree (1) to strongly agree (7) among all respondents. The figure reports on three selected technologies, comparing the least and the most prioritized technologies reported in Fig. 2 (fossil CCS on the left side and solar on the right side) with the response pattern for BECCS. 
Fig. 3. Preferences of UNFCCC delegates for investing in different technologies for longterm (2025-2050) transition to low-carbon electricity generation $(1=$ strongly disagree and 7 = strongly agree).
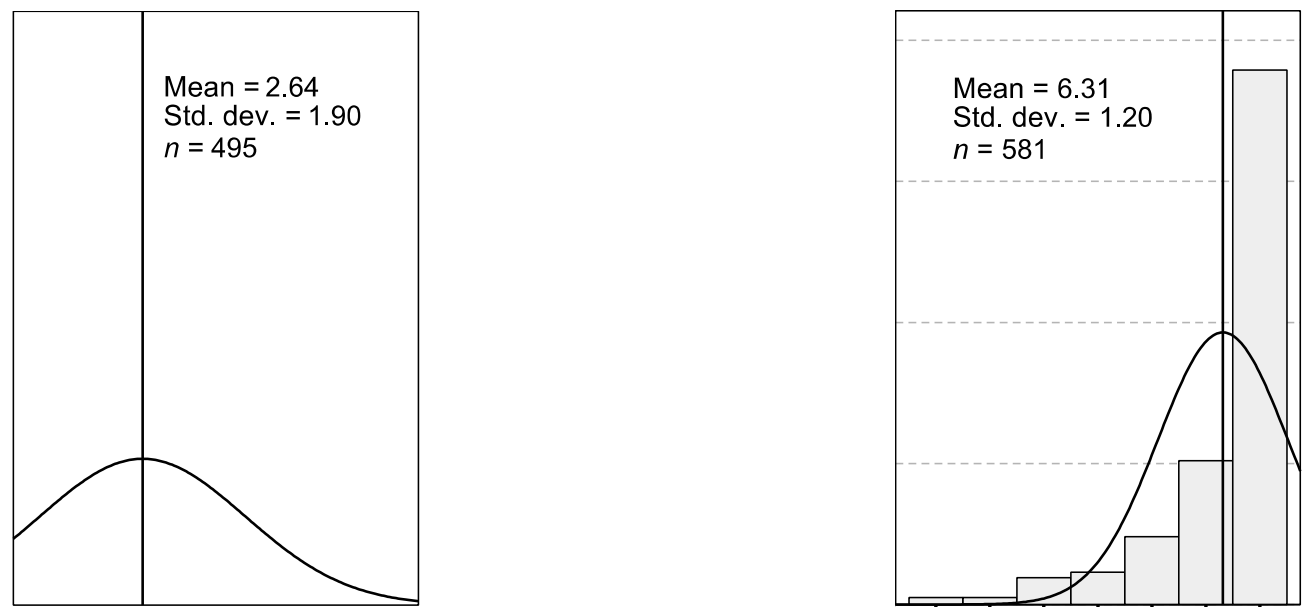

The data for BECCS are further explored by breaking down the responses according to type of respondents residing in countries belonging to different sub-regions of the global energy system.

\subsection{Regional priorities for BECCS}

Mean values of the preferences for BECCS of respondents residing in different regions of the global energy system are shown in Fig. 4. 
Fig. 4. Mean values of preferences for BECCS of respondents from different sub-regions of the global energy system.

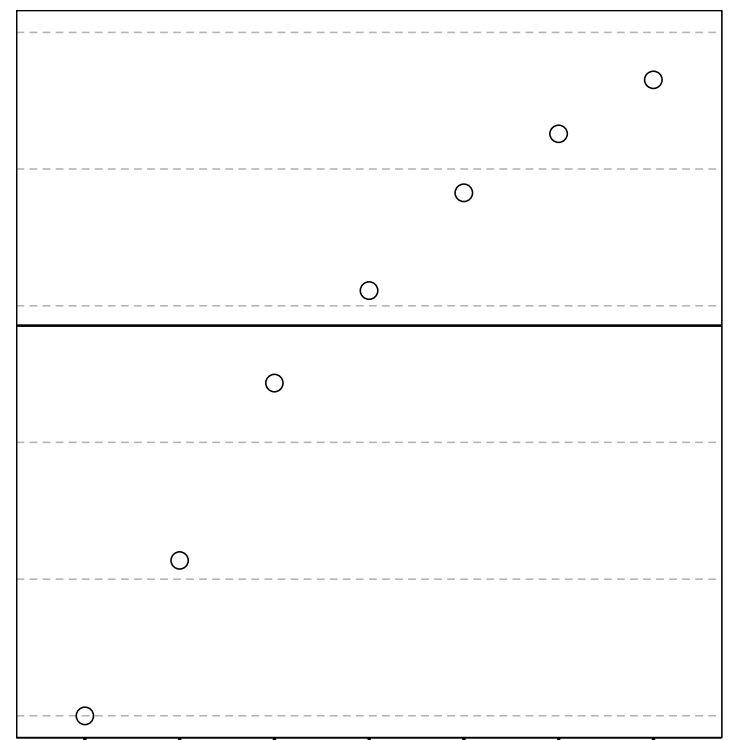

As the data are not normally distributed, as shown in Fig. 3, checking for statistically significant differences in response patterns between groups of respondents requires non-parametric tests. When comparing more than two groups, as is the case with the seven regions compared here, the Kruskal-Wallis test is considered appropriate (Conover and Iman, 1981; Kruskal and Wallis, 1952). This test determines whether at least one set of responses is statistically different from any other set. It does not require normally distributed data but it assumes that the distributions of responses are roughly the same among the groups compared. To test whether this condition is fulfilled, standard procedures are applied (i.e. a non-parametric Levine's test by calculating the difference between ranked data and group means of ranked data for each respondent followed by a one-way analysis of variance of the results). The test rejects the null hypothesis that homogeneity of variance does not exist $(p=.310)$, i.e. equal variance can be assumed.

The Kruskal-Wallis test confirms statistically significant differences, at the .01 level, between groups of respondents with different regional affiliations $(p=.005)$. Pairwise comparisons confirm statistically significant differences between NOEU and ASIA and between NOEU and LAAM at the .10 level, between OEU and AFME at the .05 level, and between OEU and ASIA and between OEU and LAAM at the .01 level.

Cross-tabulating region and responses, aggregated as disagreement or agreement that BECCS should be prioritized for investments, also enables use of a chi-square test to check whether the response patterns differ depending on the respondents' regional affiliation (Table 3). Accounting for a general positive bias in patterns of response to Likert items as described in section 3.1, responses 1-4 ("strongly disagree" to "neither agree nor disagree") are reported in Table 3 as "disagreement"; conversely, "agreement" equals 5-7 ("slightly agree" to "strongly agree"). 


\section{Table 3}

Preferences for agreeing or disagreeing with investing in BECCS according to sub-region of the global energy system.

\begin{tabular}{lcc}
\hline Region & \multicolumn{2}{c}{ BECCS } \\
& Disagreement [\%] & Agreement [\%] \\
\hline AFME & 59.4 & 40.6 \\
ASIA & 49.0 & 51.0 \\
LAAM & 56.5 & 43.5 \\
NOAM & 63.8 & 36.2 \\
NOEU & 100.0 & 0.0 \\
OCEA & 61.1 & 38.9 \\
OEU & 72.6 & 27.4 \\
N/A & 56.1 & 43.9 \\
World & 64.0 & 36.0 \\
\hline
\end{tabular}

Pearson's chi-square test confirms statistically significant differences at the .01 level $(p=.009)$.

The chi-square test for Table 3 indicates strong evidence of a relationship between region and preference for $\operatorname{BECCS}(p=.009)$.

The mean values of investment preferences for BECCS (for long-term transition of electricity production systems, i.e. 25-50 years) of respondents from different regions and the regions' technical potential for negative emissions (from electricity and biofuel production) for 2030 and 2050, as assessed by IEAGHG (IEA, 2011b), correlate at the .05 level (cf. Fig. 5); Pearson's correlation coefficient, $r$, equals 0.77 for 2030 and 0.76 for 2050. Similarly, the correlations between preferences for BECCS and the technical potential for negative emissions for electricity production only, in 2030 and 2050, also correlate at the .05 level; Pearson's $r$ equals 0.77 for 2030 and 0.78 for 2050 . 
Fig. 5. Correlation between mean values of preferences for investing in BECCS for longterm (2025-2050) transition toward low-carbon electricity production and technical potential for negative emissions for: a) electricity production in 2030, b) electricity and biofuel production in 2030, c) electricity production in 2050 , and d) electricity and biofuel production in 2050 .

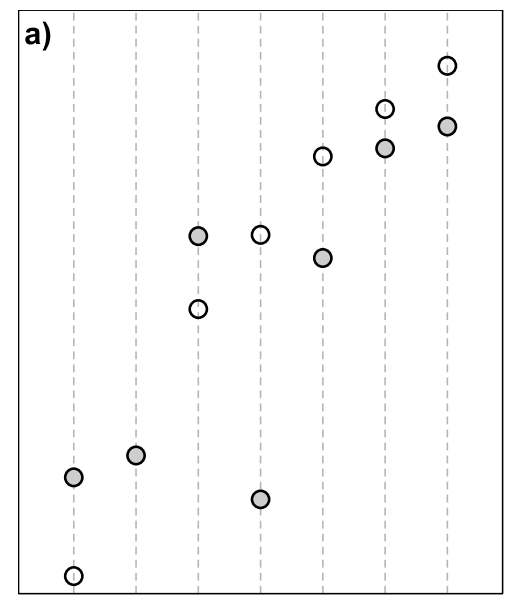

ential

Note that the $95 \%$ confidence interval around the mean values of the preferences of delegates from NOEU and OCEA is wide (mainly due to small sample sizes, cf. Table 1). The results for these regions should therefore be interpreted cautiously.

In the OCEA region, note the overrepresentation of responses from delegates residing in Australia and New Zealand, who account for $57.1 \%$ and $14.3 \%$, respectively, of respondents from OCEA. In these countries, the BECCS potential is higher than in other parts of OCEA, represented by $28.6 \%$ of respondents from OCEA, including small island developing states. The fact that the differences in the preferences and technical potential for BECCS in OCEA are relatively high, compared with the other regions, may be 
explained by the underrepresentation of OCEA respondents residing in small island states. If OCEA is excluded from the analysis, the correlation between the preferences for BECCS of respondents residing in different world regions and the regions' technical potential for BECCS is nearly perfect, in the range of $r=0.93-0.97$ (with $p$ ranging from .006 to .001$)$.

\subsection{Preferences by actor type}

The mean values of the preferences of seven types of actors are shown in Fig. 6.

Fig. 6. Preferences for investing in BECCS for long-term (2025-2050) transition to low-carbon electricity generation by actor type.

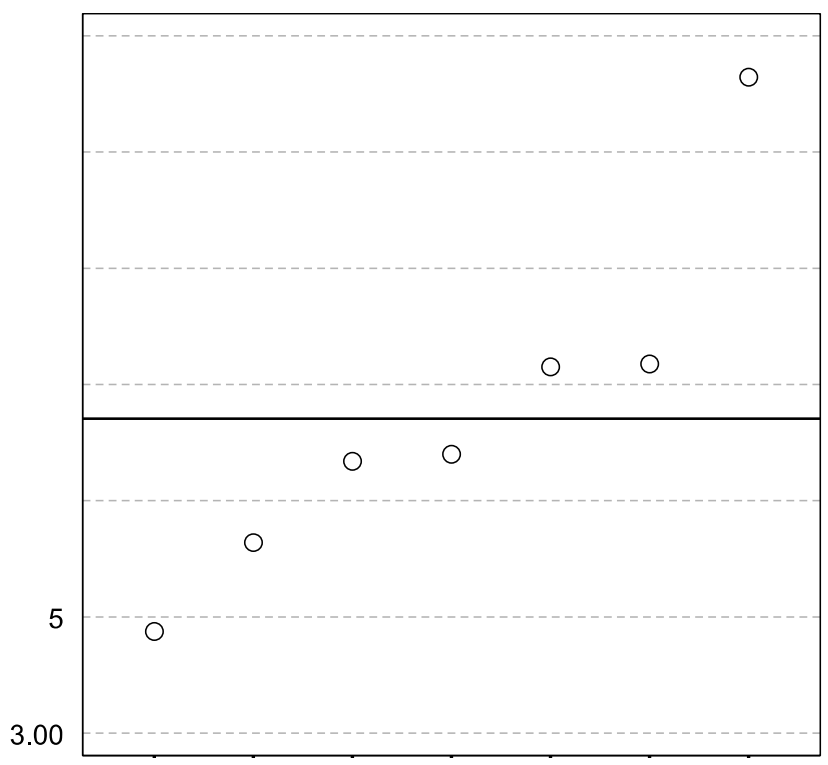

The non-parametric Levine's test rejects the null hypothesis that homogeneity of variance does not exist $(p=.855)$, i.e. the Kruskal-Wallis precondition that equal variance can be assumed is fulfilled. The Kruskal-Wallis test confirms statistically significant differences at the .01 level $(p=.005)$. Pairwise comparisons confirm statistically significant differences between government actors and RINGOs, ENGOs, and other NGOs at the .01 level and between government actors and IGOs at the .05 level.

When checking for differences between actor types in disagreement or agreement that investments in long-term transition to low-carbon electricity generation should be directed toward BECCS, the Pearson's chi-square test confirms statistically significant differences in response patterns between actor types at the .05 level ( $p=.047$ ) (cf. statistical analysis applied in relation to Table 3).

Breaking down the two large groups of actor types, i.e. state actors (governments, negotiators and IGOs) and non-state actors (all NGOs), according to regions with high potential (i.e. NOAM, AFME, LAAM, and ASIA, which are above the world's average 
potential) and low potential (i.e. OCEA, NOEU, and OEU, which are below the world's average potential) for BECCS, respondents in both groups of actor types tend to be more in favor of BECCS in regions with higher potential for BECCS (Fig. 7).

Fig. 7. State and non-state actor types' preferences for investing in BECCS for long-term (2025-2050) transition to low-carbon electricity generation according to high or low technical potential for BECCS.

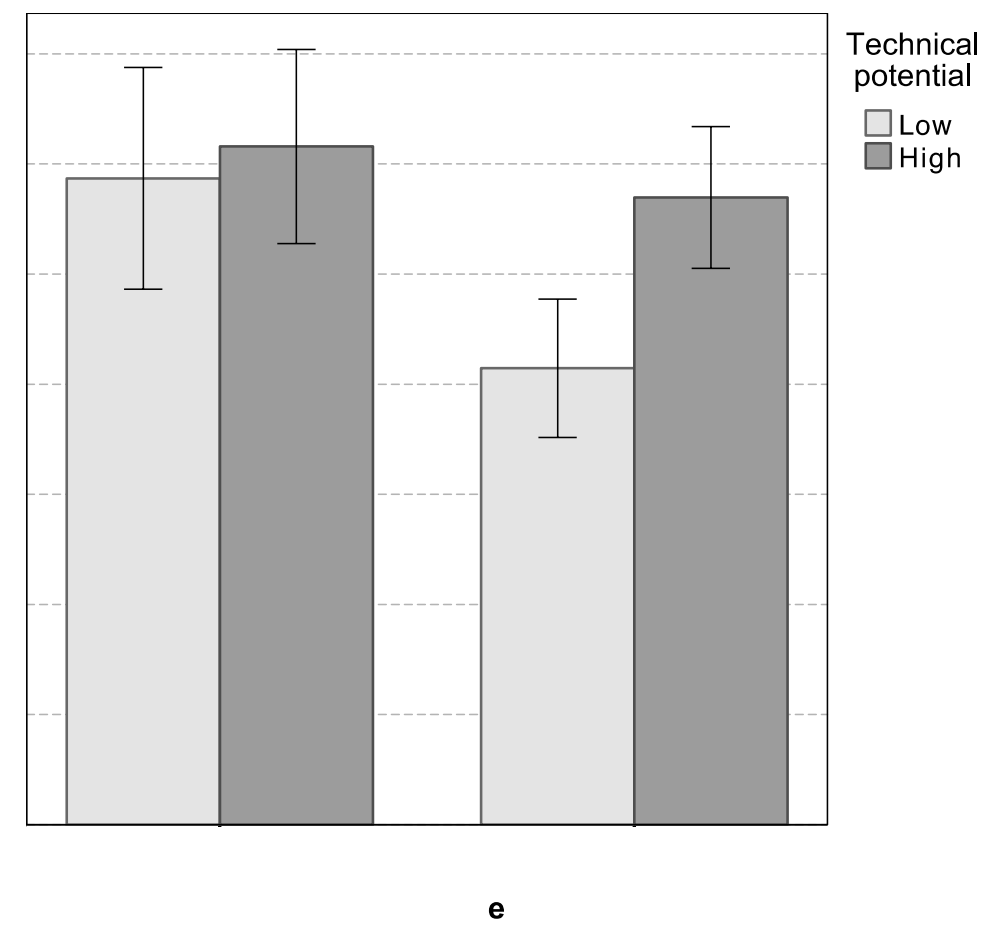

This tendency is particularly pronounced among BINGOs ( $\left.\overline{\mathrm{x}}_{\text {high }}=4.39, \overline{\mathrm{x}}_{\text {low }}=2.73\right)$ and negotiators $\left(\overline{\mathrm{x}}_{\text {high }}=4.05, \overline{\mathrm{x}}_{\text {low }}=2.70\right)$ but is also strong among ENGOs $\left(\overline{\mathrm{x}}_{\text {high }}=3.63, \overline{\mathrm{x}}_{\text {low }}=\right.$ 2.82 ) and less strong, though still evident, among RINGOS ( $\bar{x}_{\text {high }}=3.86, \bar{x}_{\text {low }}=3.45$ ). However, when comparing actor types' agreement or disagreement with prioritizing BECCS according to whether they reside in areas with high or low technological potential for BECCS (cf. procedure applied in Table 3), then differences among negotiators are only statistically significant at the .10 level, with $p=.076$ (high confidence interval due to a low $n$ when broken down into negotiators from specific regions, with 18 negotiators not having specified country of residence). Differences among BINGOs are confirmed at the .05 level $(p=.012)$ as are differences among RINGOs $(p=.044)$. Although differences among negotiators from regions with high and low technical potential can be confirmed at the .10 level, no difference can be confirmed among state actors in the aggregate (cf. Fig. 7). The general preferences of state actors are therefore not strongly related to residing in regions with high or low technical potential for BECCS.

A Kruskal-Wallis test of the differences shown in Fig. 7 confirms that there is no statistically significant difference between state actors from regions with high and low technical potential. It also confirms that responses from non-state actors from regions 
with low potential are statistically significantly different at the .01 level from all other groups of actors (i.e. state actors from regions with high and low potential as well as non-state actors from regions with high potential).

\section{Discussion}

The need to improve our understanding of the legitimacy of BECCS is urgent. If political, industrial, and public priorities result in preconditions for BECCS that disfavor deployment, then allowing an overshoot in pathways to limit temperature increase to well below $2{ }^{\circ} \mathrm{C}$ will have to rely either on other $\mathrm{CO}_{2}$-removal technologies or on relatively cheap but unproven and potentially dangerous solar radiation management technologies. Although these options may emerge as real alternatives, many of the former technologies are currently associated with even higher uncertainties and risks, while the latter are delayed by excessive risks and uncertainties and by nonexistent international governance structures (Fuss et al., 2014; Rayner et al., 2013; Smith et al., 2015; Smith, 2016; Virgoe, 2009).

Introducing a ceiling for atmospheric concentrations of greenhouse gases would, according to the models, radically increase the costs of reaching the "well below $2^{\circ} \mathrm{C}$ goal" or even put the goal beyond reach (Azar et al., 2013; Zickfeld et al., 2016). The literature, however, reports a few examples of scenarios with zero or very low levels of negative emissions that are consistent with the $2^{\circ} \mathrm{C}$ goal. All of these are, however, substantially more costly than scenarios that include negative emissions. If the goal is set to $1.5^{\circ} \mathrm{C}$, the flexibility in mitigation choices is almost nonexistent and no scenario is compatible with the goal without an overshoot in atmospheric concentrations of greenhouse gases (Rogelj et al., 2015). The consequences for today's world politics of trusting or not trusting the future ability to pursue BECCS are therefore great.

\subsection{Relative priorities}

The literature frames BECCS as a geoengineering technology as well as a mitigation technology (Clarke et al., 2014). Much of the scenario-building literature includes BECCS in a portfolio of several other mitigation options available for models when evaluating cost-effective pathways for meeting global temperature goals (Azar et al., 2013; Selosse and Ricci, 2014). On the other hand, the social science literature primarily places BECCS in a geoengineering context. Geoengineering functions as an umbrella term under which $\mathrm{CO}_{2}$ removal (e.g. BECCS) and solar radiation management (e.g. stratospheric sulfate aerosol injections) are often lumped together, despite their many differences in, for example, risks and anticipated effects on ecosystems (Bellamy et al., 2012; Linnér and Wibeck, 2015). The social science literature criticizes the literature on geoengineering technologies - BECCS included - for closing down much-needed debate. As expressed by Bellamy et al. (2012): "By narrowly appraising geoengineering proposals only against one another, legitimate alternatives are ignored and contextual isolation is facilitated" (p. 610). It is argued that assessments of BECCS need to be open to alternatives outside the realm of geoengineering. However, the scenario-building literature, framing BECCS as one mitigation technology among many, largely proves that this statement ought to be nuanced, at least for BECCS. The social science literature on BECCS also highlights that assessments of the role of $\mathrm{CO}_{2}$-removal technologies such as BECCS are based on very narrow economic and technical criteria, underscoring the need to evaluate these 
technologies along more dimensions, including social and political priorities and appraisals (Anshelm and Hansson, 2014).

This article heeds both calls from the social science literature. It relates BECCS to other mitigation technologies, as is also done in integrated assessment models. Moreover, it adds value to the above debate by extending the criteria for evaluating the role of BECCS in low-carbon transitions by studying preferences for investments among political, social, business, and climate policy research experts. The results largely mirror those of the few studies of the public understanding of BECCS (Kemper, 2015; Wallquist et al., 2012). First, BECCS is indeed seen as more prioritized for investments than is fossil CCS. The hypothesis in previous studies that the "biomass" prefix indeed matters when it comes to understanding BECCS in more positive terms than fossil CCS (Dowd et al., 2015: 4032) is supported by the present results.

That BECCS is classified as a geoengineering technology may affect political and public acceptance, and influence willingness to prioritize BECCS when investing in low-carbon transitions (Williamson, 2016). Geoengineering technologies are usually associated with negative framings, elevated by high risks. High risks have also been identified as among the strongest factors leading to low public acceptance of fossil CCS (Singleton et al., 2009) and potentially therefore also of BECCS. On the other hand, fossil CCS is usually not classified as a geoengineering technology. Still, the survey respondents prefer investment in BECCS to investment in fossil CCS. This indicates that the "biomass" prefix and promises of negative emissions to help solve the climate crisis outweigh any negative associations from placing BECCS (but not fossil CCS) in a geoengineering context.

Second, both sets of technologies - fossil CCS and BECCS - are among the least prioritized technologies for low-carbon transition management, only nuclear power being prioritized lower. This too is a pattern reported in previous literature: solar and wind power are among the most preferred mitigation technologies and CCS, whether BECCS or fossil CCS, is among the least preferred options (Dowd et al., 2015; Wallquist et al., 2012).

\subsection{Regional affiliation}

This article can demonstrate correlation between differences in BECCS prioritization among respondents from different regions and BECCS' estimated technical potential. However, this is not to say that techno-economic potential explains differences in BECCS prioritization. The detected correlation does, however, underscore the need for further inquiries into the relationships between techno-economic potential and socio-political appraisal.

When checking for a general bias in the data, the relative differences in preferences for BECCS between the regions cannot be explained by a pattern of being more positive toward all technologies in OCEA, AFME, LLAM, and ASIA (where respondents prioritize investments in BECCS higher than the world average) than in NOEU, OEU, or NOAM (prioritizing BECCS below the world average). For example: while respondents from ASIA prioritize BECCS higher than all other regions, and much higher than the average for all regions, at the same time they prioritize solar and wind lower than the average for all other regions. 
Although assessments of BECCS in the literature have attempted to account for different potentials in different regions or discussed countries with unusually high potential (IEA, 2015; Vergragt et al., 2011; Zheng and $\mathrm{Xu}, 2014$ ), this is the first study that connects these regionalized assessments with studies of political and public prioritization of BECCS in different world regions.

\subsection{Actor types}

Different types of state and non-state actors have been demonstrated to play different roles in transition management, all of which are important when challenging or conserving existing sociotechnical regimes (Amars et al., 2017; Geels, 2012). The need to pay closer attention to how different kinds of actors perceive BECCS can add substantial value to an attempt to understand the socio-political preconditions for deploying BECCS at the scales suggested by the models. In the last decade, academic interest in the role of non-state actors, relative to state actors, has grown dramatically and given rise to a wide-ranging literature on climate governance. In recent years, the call for finer granularity has been strong. It has been acknowledged, in line with the theoretical departure point of transition management theories, that non-state actors constitute an internally diverse category in which different types of actors assume different roles and articulate different priorities (Lemos and Agrawal, 2006; Nasiritousi et al., 2014).

Previous studies of BECCS' social dimension have examined the preferences and perceptions of the general public and, to a lesser extent, also of ENGOs as a specific constituency of the general public. This article indicates the importance of diversifying the "public" category to consider the preferences and perceptions of several types of non-state actors, contrasting these with the preferences and perceptions of various state actors. The data analyzed here clearly indicate that environmental NGOs' preference for BECCS is particularly low, whereas business actors are more positive toward it and national and local government representatives the most positive. Conclusions as to why this is the case are difficult to draw, but it is possible that governments, tasked with resolving the climate crisis, may want to emphasize opportunities over uncertainties. Many business actors active at UNFCCC conferences also have vested interests in developing BECCS, which could explain their stronger preferences. The fact that BECCS has been framed as a vital piece of the puzzle of cost effectively addressing climate change may support this interpretation, as cost effectiveness is a key to political decision making and successful business models (Dowd et al., 2015).

The tradition among ENGOs of scrutinizing the actions of governments and business, highlighting risks and uncertainties, may indeed explain their low preference for BECCS, a largely unproven technology associated with high risks and conflicting with goals associated with biological diversity and food security (Williamson, 2016). ENGOs are often also less sensitive to arguments for cost effectiveness, instead prioritizing environmental integrity and criticizing the economic system for failing to internalize the full costs associated with the ecological degradation caused by economic activities (cf. Betzold, 2013).

Many ENGOs have also criticized the use of bioenergy as a potentially counterproductive mitigation solution, as increased use of bioenergy crops may lead to deforestation. ENGOs also tend to stress the need to consider local welfare with regard to bioenergy production and criticize what they see as socially unsustainable practices (Arevalo et al., 2014; Söderberg and Eckerberg, 2013; van Dam and Junginger, 2011). Although 
Söderberg and Eckerberg (2013) note less contestation in debates over using biomass for producing electricity and heat than for biofuels, the tendency of ENGOs to be more skeptical towards bioenergy can also help explain their low preference for BECCS.

Note that the tendency of governmental respondents to be more positive than non-state actors toward investments in BECCS does not extend to all technology options. The response pattern for BECCS, in relative terms among the different actor types, is very similar to that for fossil CCS even though the absolute values expressing level of prioritization of fossil CCS are lower. However, there is no general favoring of investments in technologies among governmental respondents compared with NGOs. In contrast to the response patterns for BECCS, when it comes to the response pattern for wind and solar, ENGOs, RINGOs, and other NGOs are among the most positive whereas governments, BINGOs, and IGOs are less in agreement.

\subsection{State and non-state actors from regions with high or low technical potential for BECCS}

The data analyzed here also indicate that the relationship between actor type and technical potential is more complex for non-state than state actors. More data would be needed for a finer-grained analysis, but it is worth noting in relation to future studies that for some actor types, technical potential seems more related to the respondents' preferences for investing in BECCS than for other actors. Government actors seem more indifferent, with generally high preferences for BECCS no matter the regional affiliation, whereas for RINGOs, BINGOs, and negotiators, the technical potential is statistically related to their level of agreement or disagreement with the prioritizing of BECCS.

It is difficult to draw conclusions based on these findings, partly because of a lack of previous research on the topic. However, it is indeed part of normal practice for BINGOs to prioritize investments in technology based partly on its potential to function. Technological potential is a key for investment that also relates to economic potential, although business actors indeed also need to factor in, for example, institutional barriers, risks, and demand in their assessments. In this case, technological potential functions as a proxy also for the wider concept of economic potential. Although the estimation of the economic potential concludes that only approximately $1 / 3$ of the technical potential for negative emissions is likely commercially viable based on a carbon price of $€ 50 /$ ton, the relative difference in potential is roughly the same, i.e. higher in LAAM and ASIA and lower in NOEU and OEU (IEA, 2011b). It seems quite logical that this would affect prioritization among BINGOs for which market logic is part of everyday practice. It may be that government actors are less sensitive to business opportunities and more sensitive to the responsibility to act, making them willing to bear part of the R\&D cost of new technologies such as BECCS even in regions with lower potential. However, it is more difficult to explain why negotiators have more in common with BINGOs than with governmental actors. More data allowing for a higher quantitative resolution in combination with qualitative assessments would be desirable to explore the relationships identified here in more detail.

In general, more studies are needed to explore the preferences for and legitimacy of BECCS. At present, the socio-political legitimacy of BECCS is gravely understudied, so proactive studies of legitimacy aspects are greatly needed. Due to inertia in the climate system, BECCS cannot be applied as an "emergency brake" technology in the event of failed climate policy (Azar et al., 2013; Zickfeld et al., 2016). In most assessments of how 
to meet the "well below $2^{\circ} \mathrm{C}$ goal," BECCS is essential, alongside other mitigation options and measures to reduce demand. Therefore, if BECCS does not materialize, it may force the world into elevated climate change or to apply other $\mathrm{CO}_{2}$-removal technologies or potentially dangerous solar radiation management geoengineering technologies.

\section{Conclusions and Policy Implications}

This article reports on UNFCCC conference delegates' prioritization of investments in bioenergy with carbon capture and storage (BECCS) for the long-term transition to low-carbon electricity generation systems. It demonstrates that BECCS is assigned a relatively lower priority than are alternative low-carbon energy technologies, such as solar and wind power, but a higher priority than fossil energy CCS or nuclear power. Investment preferences for BECCS in different world regions correlate positively with their technical potential for BECCS. The article can also confirm that different types of actors prioritize differently, with environmental NGOs being the most skeptical and government actors the most positive toward BECCS. As such, this article both confirms previous literature that BECCS is prioritized lower than renewables but higher than conventional CCS and nuances previous literature in that it finds differences in attitudes depending on both regional affiliation and actor type.

The article presents a unique preliminary mapping of how investments in BECCS are prioritized in transition management. The response patterns can serve to contextualize research into the broader issue of legitimacy. This article offers further evidence that the model results must be seen in the context of both the techno-economic uncertainties of and socio-political preconditions for BECCS. On the other hand, the model results indicate that mitigation choices are limited for pathways associated with holding global warming well below $2^{\circ} \mathrm{C}$ and are almost nonexistent for $1.5^{\circ} \mathrm{C}$ pathways. They also indicate that BECCS is a key technology in both pathways.

If the indications of low preferences for investments in BECCS, identified here, are confirmed by further studies, research into the consequences for the climate policymaking communities as well as for the possibilities of reaching various temperature goals will be greatly needed. Low preferences can be a barrier to carbon price policy design that incentivizes BECCS deployment, particularly subsidies or other instruments that reward negative emissions. Lack of substantial deployment of BECCS in attempts to meet the $2^{\circ} \mathrm{C}$ goal, in turn, would probably require exploring other $\mathrm{CO}_{2}$-removal technologies that are currently not represented in the integrated assessment models. For the $1.5^{\circ} \mathrm{C}$ goal, all models predict that limiting the use of BECCS would require applying other $\mathrm{CO}_{2}$-removal technologies or applying potentially dangerous solar radiation geoengineering technologies.

\section{Acknowledgements}

This work was supported by the Swedish Energy Agency [grant number 42390-1], the Swedish Research Council VR [grant number 2016-06359] and the Swedish Research Council Formas [grant numbers 2012-725 and 2016-00958]. The author thanks the anonymous reviewers and Mattias Hjerpe for their very constructive and insightful comments on previous versions of this article. 


\section{References}

Amars, L., Fridahl, M., Hagemann, M., Röser, F., Linnér, B.-0., 2017. The transformational potential of Nationally Appropriate Mitigation Actions in Tanzania: assessing the concept's cultural legitimacy among stakeholders in the solar energy sector. Local Environ. 22 (1), 86-105.

Anshelm, J., Hansson, A., 2014. The last chance to save the planet? An analysis of the geoengineering advocacy discourse in the public debate. Environ. Humanit. 5, 101-123.

Ansolobehere, S., Beer, J., Deutch, J., Ellerman, A.D., Friedman, J., Herzog, H., . . S Steinfeld, E., 2007. The future of coal: Options for a carbon constrained world. MIT Press, Cambridge, MA.

Ashworth, P., Einsiedel, E., Howell, R., Brunsting, S., Boughen, N., Boyd, A., . . . Hekkenberg, M., 2013. Public Preferences to CCS: How does it Change Across Countries? Energy Procedia 37, 7410-7418.

Arevalo, J., Ochieng, R., Mola-Yudego, B., Gritten, D., 2014. Understanding bioenergy conflicts: Case of a jatropha project in Kenya's Tana Delta. Land Use Policy 41, 138-148.

Azar, C., 2011. Biomass for energy: a dream come true... or a nightmare? WIREs Clim. Chang. 2 (3), 309-323.

Azar, C., Holmberg, J. 1995. Defining the generational environmental debt. Ecol. Econ. 14 (1), 7-19.

Azar, C., Johansson, D.J.A., Mattsson, N., 2013. Meeting global temperature targets: The role of bioenergy with carbon capture and storage. Environ. Res. Lett. 8 (3), 1-8.

Azar, C., Lindgren, K., Obersteiner, M., Riahi, K., Vuuren, D.P.v., den Elzen, K.M.G.J., . . . Larson, E.D., 2010. The feasibility of low CO2 concentration targets and the role of bio-energy with carbon capture and storage (BECCS). Clim. Chang. 100 (1), 195-202.

Bellamy, R., Chilvers, J., Vaughan, N.E., Lenton, T.M., 2012. A review of climate geoengineering appraisals. WIREs Clim. Chang. 3 (6), 597-615.

Betzold, C., 2013. Business insiders and environmental outsiders? Advocacy strategies in international climate change negotiations. Interest Groups and Advocacy 2 (3), 302-322.

Bradshaw, J., Bachu, S., Bonijoly, D., Burruss, R., Holloway, S., Christensen, N.P., Mathiassen, O.M., 2007. CO2 storage capacity estimation: Issues and development of standards. Int. J. of Greenh. Gas Control 1(1), 62-68.

Carbo, M.C., Smit, R., van der Drift, B., Jansen, D., 2011. Bio energy with CCS (BECCS): Large potential for BioSNG at low $\mathrm{CO}_{2}$ avoidance cost. Energy Procedia 4, 29502954.

Carifio, J., Perla, R.J., 2007. Ten common misunderstandings, misconceptions, persistent myths and urban legends about Likert scales and Likert response formats and their antidotes. J. of Soc. Sci. 3 (3), 106-116.

Clarke, L., Jiang, K., Akimoto, K., Babiker, M., Blanford, G., Fisher-Vanden, K., Hourcade, J.-C., Krey, V., Kriegler, E., Löschel, A., McCollum, D., Paltsev, S., Rose, S., Shukla, P. R., Tavoni, M., van der Zwaan, B. C. C., van Vuuren, D. P., 2014. Assessing transformation pathways. In: Climate change 2014: Mitigation of climate change. Contribution of Working Group III to the Fifth Assessment Report of the Intergovernmental Panel on Climate Change (Eds. Edenhofer, O. et al.). Cambridge, UK \& New York: Cambridge University Press.

Conover, W.J., Iman, R.L., 1981. Rank transformations as a bridge between parametric and nonparametric statistics. The Am. Statistician 35 (3), 124-129. 
Dowd, A.-M., Rodriguez, M., Jeanneret, T., 2015. Social science insights for the BioCCS industry. Energies 8 (5), 4024-4042.

Fridahl, M., Linnér, B.-0., 2015. Perspectives on the Green Climate Fund: Possible compromises on capitalization and balanced allocation. Clim. and Dev. 8 (2), 105109.

Friman, M., Hjerpe, M., 2015. Agreement, significance, and understandings of historical responsibility in climate change negotiations. Clim. Policy 24 (2), 237-264.

Fuss, S., Canadell, J.G., Peters, G.P., Tavoni, M., Andrew, R.M., Ciais, P., . . Yamagata, Y., 2014. Betting on negative emissions. Nat. Clim. Chang. 4, 850-853.

Geels, F.W., 2012. A socio-technical analysis of low-carbon transitions: introducing the multi-level perspective into transport studies. J. of Transp. Geogr. 24, 471-482.

Gerland, P., Raftery, A.E., Ševčíková, H., Li, N., Gu, D., Spoorenberg, T., . . . Wilmoth, J., 2014. World population stabilization unlikely this century. Sci. 346 (6206), 234237.

González-Eguino, M., 2015. Energy poverty: An overview. Renewable and Sustainable Energy Rev. 47, 377-385.

Gough, C., Upham, P., 2011. Biomass energy with carbon capture and storage (BECCS or Bio-CCS). Greenh. Gas: Sci. and Techno. 1 (4), 324-334.

Gough, C., Vaughan, N.E., 2015. Synthesising existing knowledge on the feasibility of BECCS. UK Met Office, London.

Grönkvist, S., Möllersten, K., Pingoud, K., 2006. Equal opportunity for biomass in greenhouse gas accounting of $\mathrm{CO}_{2}$ capture and storage: A step towards more cost-effective climate change mitigation regimes. Mitig. and Adapt. Strateg. for Glob. Chang. 11 (5), 1083-1096.

Haszeldine, R.S., 2009. Carbon capture and storage: How green can black be? Sci. 325 (5948), 1647-1652.

Hjerpe, M., Nasiritousi, N., 2015. Views on alternative forums for effectively tackling climate change. Nat. Clim. Chang. 5, 864-867.

Humpenöder, F., Popp, A., Dietrich, J.P., Klein, D., Lotze-Campen, H., Bonsch, M., . . . Müller, C., 2014. Investigating afforestation and bioenergy CCS as climate change mitigation strategies. Environ. Res. Lett. 9 (6), 1-13.

IEA, 2011a. Combining bioenergy with CCS: Reporting and accounting for negative emissions under UNFCCC (United Nations Framework Convention on Climate Change) and the Kyoto Protocol. International Energy Agency, Paris.

IEA, 2011b. Potential for biomass and carbon capture and storage. International Energy Agency's Greenhouse Gas R\&D Programme, Celtenham.

IEA, 2013. Redrawing the energy-climate map: World energy outlook special report. The International Energy Agency, Paris.

IEA, 2014. CCS 2014: What lies in store for CCS? The International Energy Agency, Paris.

IEA, 2015. Global energy-related emissions of carbon dioxide stalled in 2014. The International Energy Agency, Paris.

IPCC, 2005. Special report on carbon dioxide capture and storage. (Eds. Metz, B., Davidson, O., de Coninck, H., Loos, M., Meyer, M.). Cambridge University Press, Cambridge and New York.

IPCC, 2011. Special report on renewable energy sources and climate change mitigation. (Eds. Edenhofer, O., Pichs-Madruga, R., Sokona, Y., Seyboth, K., Matschoss, P., Kadner, S., Zwickel, T., Eickemeier, P., Hansen, G., Schlömer, S., von Stechow, C.). Cambridge University Press, Cambridge and New York. 
IPCC, 2013. Climate change 2013: The physical science basis. Contribution of Working Group I to the Fifth Assessment Report of the Intergovernmental Panel on Climate Change. (Eds. Stocker, T.F., Qin, D., Plattner, G.-K., Tignor, M. Allen, S.K., Boschung, J., Nauels, A., Xia, Y., Bex, V., Midgley, P.M.). Cambridge University Press. Cambridge and New York.

IPCC, 2014. Climate change 2014: Mitigation of climate change. Contribution of Working Group III to the Fifth Assessment Report of the Intergovernmental Panel on Climate Change. (Eds. Edenhofer, O. et al.). Cambridge University Press, Cambridge \& New York.

Jenkins, C.R., Cook, P.J., Ennis-King, J., Undershultz, J., Boreham, C., Dance, T., ... Urosevic, M., 2012. Safe storage and effective monitoring of $\mathrm{CO} 2$ in depleted gas fields. PNAS 109 (2), 35-41.

Johns, R., 2005. One size doesn't fit all: Selecting response scales for attitude items. J. of Elections, Public Opin. and Parties 15 (2), 237-264.

Karimi, F., Goulas, A., Barzmehri, M.M., Putri, M.A., 2012. CCS potential in Norway Exploring the role of flagship projects: The Mongstad and Kårstø case studies. Int. J. of Sustain. Water and Environ. Syst. 4 (1), 23-34.

Karlsson, C., Hjerpe, M., Parker, C., Linnér, B.-0., 2012. The Legitimacy of leadership in international climate change negotiations. Ambio 41 (1), 46-55.

Kemper, J., 2015. Biomass and carbon dioxide capture and storage: A review. Int. J. of Greenh. Gas Control 40, 401-430.

Klein, D., Bauer, N., Bodirsky, B., Dietrich, J.P., Popp, A., 2011. Bio-IGCC with CCS as a long-term mitigation option in a coupled energy-system and land-use model. Energy Procedia 4, 2933-2940.

Kruskal, W.H., Wallis, W.A., 1952. Use of ranks in one-criterion variance analysis. J. of the Am. Statistical Assoc. 47 (260), 583-620.

L'Orange Seigo, S., Dohle, S., Siegrist, M., 2014. Public perception of carbon capture and storage (CCS): A review. Renew. and Sustain. Energy Rev. 38, 848-863.

Lemos, M.C., Agrawal, A., 2006. Environmental governance. Annu. Rev. of Environ. and Resour. 31 (1), 297-325.

Leung, D.Y.C., Caramanna, G., Maroto-Valer, M. M., 2014. An overview of current status of carbon dioxide capture and storage technologies. Renewable and Sustainable Energy Rev. 39, 426-443.

Likert, R., 1932. A technique for the measurement of attitudes. Arch. of Psychol. 22 (140), 55.

Linnér, B.-O., Wibeck, V., 2015. Dual high-stake emerging technologies: a review of the climate engineering research literature. WIREs Clim. Chang. 6 (2), 255-268.

Luckow, P., Wise, M.A., Dooley, J.J., Kim, S.H., 2010. Large-scale utilization of biomass energy and carbon dioxide capture and storage in the transport and electricity sectors under stringent $\mathrm{CO}_{2}$ concentration limit scenarios. Int. J. of Greenh. Gas Control 4 (5), 865-877.

Nasiritousi, N., Hjerpe, M., Buhr, K., 2014. Pluralising climate change solutions? Views held and voiced by participants at the international climate change negotiations. Ecol. Econ. 105, 177-184.

Nasiritousi, N., Hjerpe, M., Linnér, B.-O., 2014. The role of non-state actors in climate change governance: Understanding agency through governance profiles. Int. Environ. Agreements 16 (1), 109-126.

Popp, A., Rose, S.K., Calvin, K., Vuuren, D.P.V., Dietrich, J.P., Wise, M., . . Kriegler, E., 2014. Land-use transition for bioenergy and climate stabilization: model comparison of 
drivers, impacts and interactions with other land use based mitigation options. Clim. Chang. 123 (3-4), 495-509.

Rayner, S., Heyward, C., Kruger, T., Pidgeon, N., Redgwell, C., Savulescu, J., 2013. The Oxford Principles. Clim. Chang. 121, 499-512.

Ricci, 0., 2012. Providing adequate economic incentives for bioenergies with $\mathrm{CO}_{2}$ capture and geological storage. Energy Policy 44, 362-373.

Rogelj, J., Luderer, G., Pietzcker, R.C., Kriegler, E., Schaeffer, M., Krey, V., Riahi, K., 2015. Energy system transformations for limiting end-of-century warming to below $1.5^{\circ} \mathrm{C}$. Nat. Clim. Chang. 5 (6), 519-527.

Sanchez, D.L., Callaway, D.S., 2016. Optimal scale of carbon-negative energy facilities. Appl. Energy 170, 437-444.

Schuman, H., Presser, S., 1981. Questions and answers in attitude surveys: Experiments on question form, wording, and context. Academic Press, New York.

Selosse, S., Ricci, 0., 2014. Achieving negative emissions with BECCS (bioenergy with carbon capture and storage) in the power sector: New insights from the TIAM-FR (TIMES Integrated Assessment Model France) model. Energy 76, 967-975.

Singleton, G., Herzog, H., Ansolabehere, S., 2009. Public risk perspectives on the geologic storage of carbon dioxide. Int. J. of Greenh. Gas Control 3 (1), 100-107.

Smith, A., Voß, J.-P., Grin, J., 2010. Innovation studies and sustainability transitions: The allure of the multi-level perspective and its challenges. Res. Policy 39 (4), 435448.

Smith, P., 2016. Soil carbon sequestration and biochar as negative emission technologies. Glob. Chang. Biol. 22 (3), 1315-1324.

Smith, P., Davis, S.J., Creutzig, F., Fuss, S., Minx, J., Gabrielle, B., . . Yongsung, C., 2016. Biophysical and economic limits to negative $\mathrm{CO}_{2}$ emissions. Nat. Clim. Chang. 6 (1), 42-50.

Söderberg, C., Eckerberg, K., 2013. Rising policy conflicts in Europe over bioenergy and forestry. For. Policy and Econ. 33, 112-119.

Tokimatsu, K., Yasuoka, R., Nishio, M., 2016. Global zero emissions scenarios: The role of biomass energy with carbon capture and storage by forest land use. Appl. Energy 185, 1899-1906.

UNFCCC, 2016. COP21 report (addendum 1), Paris 2015. FCCC/CP/2015/10/Add.1. UN Framework Convention on Climate Change, Bonn.

van Dam, J., Junginger, M., 2011. Striving to further harmonization of sustainability criteria for bioenergy in Europe: Recommendations from a stakeholder questionnaire. Energy Policy 39 (7), 4051-4066.

Vergragt, P.J., Markusson, N., Karlsson, H., 2011. Carbon capture and storage, bio-energy with carbon capture and storage, and the escape from the fossil-fuel lock-in. Glob. Environ. Chang. 21 (2), 282-292.

Virgoe, J., 2009. International governance of a possible geoengineering intervention to combat climate change. Clim. Chang. 95 (1-2), 103-119.

Wallquist, L., Seigo, S.L.O., Visschers, V.H.M., Siegrist, M., 2012. Public acceptance of CCS system elements: A conjoint measurement. Int. J. of Greenh. Gas Control 6 (1), 77-83.

Wennersten, R., Sun, Q., Li, H., 2014. The future potential for Carbon Capture and Storage in climate change mitigation-an overview from perspectives of technology, economy and risk. J. of Cleaner Prod. 103, 724-736.

Williamson, P., 2016. Emissions reduction: Scrutinize $\mathrm{CO}_{2}$ removal methods. Nat. 530, 153-155. 
Zheng, B., Xu, J., 2014. Carbon capture and storage development trends from a technoparadigm perspective. Energies 7 (8), 5221-5250.

Zickfeld, K., MacDougall, A.H., Matthews, H.D., 2016. On the proportionality between global temperature change and cumulative $\mathrm{CO}_{2}$ emissions during periods of net negative $\mathrm{CO}_{2}$ emissions. Environ. Res. Lett. 11 (5), 1-9.

Zoback, M.D., Gorelick, S.M., 2012. Earthquake triggering and large-scale geologic storage of carbon dioxide. PNAS 109 (26), 10164-10168. 